\title{
Systemic Input-Output Computation of Green and Blue Virtual Water 'Flows' with an Illustration for the Mediterranean Region
}

\author{
M. Antonelli $\cdot$ R. Roson • M. Sartori
}

Received: 18 February 2012 / Accepted: 29 August 2012 /

Published online: 11 September 2012

(C) Springer Science+Business Media B.V. 2012

\begin{abstract}
The term virtual water refers to the volume of water used in the production of a commodity or service. Accordingly, virtual water 'trade' is the amount of water 'embedded' in commodities being transferred from one place to another as a consequence of trade. This paper argues that the conventional methods so far adopted for the computation of virtual water 'flows' (based on Hoekstra and Hung 2002) have considered only direct water usage and not sufficiently distinguished between blue and green water resources. This has brought about flawed estimates of virtual water 'flows', thereby limiting the usefulness of the virtual water concept as a tool for informing water policy. A novel approach for computing virtual water 'flows' which applies the Input-output (IO) methodology to account for both direct and indirect water consumption, and simultaneously distinguishes between the different typologies of water, is presented. The study upholds that the integration of these two methods can not only provide a more robust framework for quantifying virtual water 'flows', but also enhance the relevance of the concept as a tool for water resource management policy. The implications of these alternative estimation methods are here illustrated using data referring to 11 Mediterranean economies and 7 internationally traded agricultural commodities.
\end{abstract}

Keywords Virtual water Input-output · Green and blue water - Mediterranean region

\author{
M. Antonelli \\ King's College, London, UK \\ R. Roson $(\bowtie)$ \\ Department of Economics, Ca'Foscari University, Venice, Italy \\ e-mail: roson@unive.it \\ M. Sartori \\ University of Milan, Milan, Italy \\ R. Roson \\ IEFE, Bocconi University, Milan, Italy \\ R. Roson - M. Sartori \\ CMCC, Lecce, Italy
}




\section{Introduction}

The concept of virtual water has steadily gained prominence as a metaphor to illustrate the relationships between water inputs and industry outputs. The term refers to the volume of water used in the production of a commodity or a service. Accordingly, virtual water 'trade' is the amount of water 'embedded' in internationally traded commodities. ${ }^{1}$ Traditionally, virtual water 'flows' are calculated using the methodology developed by Hoekstra and Hung in 2002. The basic approach is to multiply output or trade flows (ton/yr) by the associated virtual water content $\left(\mathrm{m}^{3} /\right.$ ton $)$ of the produced or traded commodity. In computing virtual water 'flows', this accounting method considers only direct, i.e. final, water usage, ${ }^{2}$ thus ignoring the many indirect, i.e. intermediate, uses of the resource as a fundamental input to production. Virtual water studies have mainly focused on the water-saving effect brought about by international food trade and on the role it plays in compensating for local water deficits. Few of them, however, have established whether the water used in the production process originates from surface and underground flow (hereby referred to as blue water), or from water stored in the root zone (green water). None, to our knowledge, has applied the Input-output (IO) methodology to assess the virtual water 'flows' associated with international trade and simultaneously assessed the "colour" of the 'exchanged' water. Distinguishing between blue and green water is important, because only the former has a significant opportunity cost and can be controlled (possibly only partially) by water management bodies.

This paper examines the standard virtual water accounting method based on Hoekstra and Hung (2002) and seeks to overcome two of its fundamental shortcomings: i) the lack of a systemic account of water production factors; and ii) the absence of a distinction between blue and green water resources. These flaws appear to undermine both the reliability of current estimates and the applicability of the concept as a tool for informing water resource management policy. This study is therefore aimed at presenting a comprehensive analysis of virtual water 'trade' that integrates these two different but complementary approaches. Firstly, a systemic quantification of virtual water 'flows' by means of the Input-output framework is presented. Secondly, the green and blue water components 'embedded' in traded commodities are differentiated.

The implications of the alternative estimation approaches are illustrated here using data referring to 11 Mediterranean-rim economies. The Mediterranean test case is presented with the sole purpose of highlighting how the new methodology can essentially change the results, possibly bringing about different policy implications. The Mediterranean is also chosen as it has been considered by many previous virtual water analyses.

The study is structured as follows: the next section outlines the background of the paper and reviews the relevant literature; the third part describes the methodology which has been deployed and its advantages over conventional approaches; the fourth section presents and discusses the test case results, highlighting the extent to which the improved methodology can make virtual water a more meaningful and useful concept for policy assessments; the final part draws some conclusions.

\footnotetext{
${ }^{1}$ The terms 'trade', 'flows', 'imports' and 'exports' when associated with virtual water will be used throughout with inverted commas, the reason being that it is in fact goods that are being traded, not water (Merrett 2003).

${ }^{2}$ Only in a few cases, more specifically with regards to livestock products, some intermediate inputs accounted for, thus making the estimates internally inconsistent.
} 


\section{Background}

\subsection{The Concept of Virtual Water}

Virtual water 'trade' is the market-mediated mechanism through which arid and semi-arid countries, like most Mediterranean economies, have indirectly and implicitly coped with water scarcity. The concept of virtual water was identified and made popular by Allan (1993). The 'exchange' of virtual water is implicit in trade: whenever a country imports (exports) food and manufactured commodities from another, a virtual 'transfer' of water occurs (Allan 1998). Virtual water is an "inherently economic concept", which is consistent with standard international trade theory (Reimer 2012). Virtual water 'flows' between nations are substantial, accounting for over 1,000 billion cubic metres annually (Hoekstra and Hung 2002; Chapagain and Hoekstra 2003; Zimmer and Renault 2003; Oki et al. 2003). North and South America, Australia, most of Asia and central Africa are major 'exporters' of virtual water. Europe, Japan, the Middle East, North and Southern Africa, Mexico and Indonesia are net virtual water 'importers'.

Commodities are produced and exported by economies, which can undertake production processes in an economically competitive way. Therefore, water-intensive products are likely to be produced in places where water is relatively cheap, although water is not the only production factor and the low price of other factors (e.g., labour, land) may actually be more important to determine the production profile of a country. Water is cheap where it is abundant, but the opposite is not necessarily true: water resources may not be correctly priced and property rights may not be adequately enforced, so that the cost of water could be kept artificially low.

Nonetheless, to the extent that water abundance determines a comparative advantage in water-intensive sectors, countries facing water shortage can achieve some savings by importing high-water goods (e.g., water intensive agricultural products), rather than producing them internally, in exchange for low-water goods and services. As a consequence, while there is no actual water saving in commodity trade, trade does enable very significant advances in food and water security to be achieved. This is to say that although the 'import' of virtual water does not actually bring about real water savings, the capacity to engage in trade provides water scarce countries with water and food security. Virtual water 'trade' is thus a securitising rather than a 'saving' process. However, as virtual water generally 'moves' from regions that achieve high returns to water (especially green water), the result is a saving at the global level when the 'imports' are to economies that achieve poor returns to water.

Two remarks are in order here. First, the virtual water 'trade' mechanism operates smoothly and silently through the markets, so that virtual water 'trade' is not part of any water policy package. Second, what we are discussing here with reference to water applies equally well to any other scarce resource. ${ }^{3}$ Indeed, it is well known that the main implication of competitive trade is a more efficient global allocation of resources.

Virtual water is, therefore, a useful metaphor which helps shedding light on the water efficiency gains associated with regional and international trade. In order to enhance its policy relevance, however, it is imperative to refine the current analysis by i) considering

\footnotetext{
${ }^{3}$ The notion has been used, for instance, to assess the 'virtual' carbon content of imports - i.e. the extent to which carbon is embodied in the international trade of goods and services - (Atkinson et al. 2010). Virtual water has also been linked to of water footprint, which is "the volume of water necessary to produce the good and services consumed by the inhabitants of a country" (Chapagain and Hoekstra 2004).
} 
water consumption in its both direct and indirect components; ii) distinguishing the different sources of water and their opportunity costs.

\subsection{Computing Virtual Water Flows Using IO Accounting}

The basic approach for calculating virtual water 'trade' flows was developed by Hoekstra and Hung (2002). Virtual water 'flows' between countries $\left(\mathrm{m}^{3} /\right.$ year) are calculated by multiplying commodity trade flows (ton/year or $\$ /$ year) by their associated virtual water content $\left(\mathrm{m}^{3} /\right.$ ton or $\left.\mathrm{m}^{3} / \$\right)$. The virtual water content of a product, in turn, is the volume of water required to produce the commodity in the exporting country. Therefore:

$$
v w t_{i}^{r s}=c t_{i}^{r s} \times w_{i}^{r}
$$

Where $v w t$ is the virtual water 'trade' flow $\left(\mathrm{m}^{3} /\right.$ year) from the exporting country $r$ to the importing country $s$ as a result of trade in crop $i$. ct represents the crop trade flow from the exporting country $r$ to the importing country $s$ for crop $i$ and $w$ is the specific unit water demand of crop $i$ in the exporting country (all variables are possibly functions of time). It is assumed that if a crop is exported from a certain country to another, this crop has been grown in the exporting country. This is not always the case, but it is a reasonable approximation.

Input-output analysis (Leontief 1951) can be used to get more accurate estimates of virtual water flows. In a nutshell, IO tables express the value of economic transactions occurring between different sectors of an economy, so that it is possible to account for sectoral interdependencies in the economic system. These affect, for example, how demand in one industry stimulates production not only in that industry, but in all other industries supplying intermediate factors to the former. Over the past few years, a number of scholars have used input-output data and models to analyse regional and national water consumption (Dabo and Hubacek 2007; Dietzenbacher and Velázquez 2006; Dietzenbacher and Velázquez 2007; Feng et al. 2011; Huang et al. 2011; Lenzen and Peters 2010; Velázquez 2006; Wang et al. 2009; Yu et al. 2010; Zhang et al. 2010, 2011; Zhao et al. 2009, 2010). Whereas these studies focus on one national economy, in this work we propose to extend the application of IO techniques to international trade flows.

In order to understand how the Input-Ouput analysis can be applied in practice, we consider a matrix A where each element $a_{i j}$ stands for consumption of good $i$ (produced by industry $i$ or not produced, like water $w$, being a primary resource) necessary to produce one unit of good $j$ (produced by industry $j$ ). We shall refer to direct water consumption in industry $j$ as $a_{w j}$. Direct water requirements do not express the actual usage of water per unit of output, though, as one should account for water employed in the production of intermediate factors, whose amount is $a_{w j} \times a_{i j}$ per unit of output. As production of intermediate factors itself requires intermediate factors, with additional request of water, the computation of global, systemic water input would imply the calculation of an infinite sum which, nonetheless, can be shown to converge to a finite number. For example, for two goods ( 1 and 2$)$ the unitary water requirement for good 1 is not only $a_{w 1}$, but actually:

$$
a_{w 1}+a_{21} a_{w 2}+a_{12} a_{21} a_{w 1}+a_{12} a_{21}^{2} a_{w 2}+a_{12}^{2} a_{21}^{2} a_{w 1}+\ldots
$$

It is not necessary to calculate the infinite sum above for all goods, however, as it is possible to easily compute global water input coefficients using a compact matrix notation. Denoting $A$ the square matrix of intermediate input output coefficients in a country $a_{i j}, w^{4}$ the

\footnotetext{
$\overline{{ }^{4} \text { It is the same as vector } w \text { in Eq. }}$ (1).
} 
(row) vector of $a_{w j}$ coefficients, and $v$ the (row) vector of global (systemic, namely direct plus indirect) unit water requirements, then:

$$
v=w(I-A)^{-1}
$$

In order to calculate systemic virtual water trade, each element in the vector $v$ would replace the corresponding variable $w$ into Eq. (1).

Equation (3) can also be used to provide estimates of global water usage for specific water components. For example, to get estimates of systemic unit demand for blue water resources, it is sufficient to reinterpret the vector $w$ in (3) as sectoral blue water input per unit of output. Furthermore, if it is assumed (as it is done in this paper) that the share of blue water in total water consumption does not vary by industry (though it may vary by country), it is enough to multiply either the vector $v$ or the vector $w$ by the share of blue water in the total water usage.

\subsection{Distinguishing Green and Blue Water Resources}

Not all water is equal. Water resources differ in terms of origin, relative scarcity, mobility, possible allocation and opportunity costs. For policy purposes, it is especially important to distinguish between two different types of water which, for ease of communication, are referred to as blue and green water. The term blue water refers to water stored in lakes, rivers, reservoirs, ponds and aquifers (Rockström et al. 1999). Green water indicates the return flow of water to the atmosphere as evapotranspiration, which includes a productive role in the biosphere - as transpiration, and a non-productive biospheric role - as direct evaporation from the surface of soils, lakes, ponds, and from water intercepted by canopies (Falkenmark 1995; Yang et al. 2006). The former can be diverted to irrigate crops as a supplement to rainfall; the latter sustains rainfed crop production as well as natural vegetation.

Blue and green water resources differ in many aspects, and their ratio varies substantially over time and space. Green water supply comes from rainfall and is scarce in arid and semiarid areas. As such it is highly immobile and in general is not explicitly valued by users. ${ }^{5}$ Conversely, blue water is mobile - it can be abstracted, pumped, stored, treated, distributed, collected, and recycled. Normally, its supply is costly, because it requires infrastructure. Green water supports human livelihoods through rainfed crop production as well as ecosystems, and faces no major competition from other domestic or industrial uses. Therefore, it has a low opportunity cost compared with the one of blue water. Blue water, instead, is the water with the highest economic potential, as it can perform numerous functions. ${ }^{6}$ Holding other factors constant, trading green virtual water is more efficient than trading blue virtual water (Yang et al. 2006; Chapagain et al. 2006). The reason is that the blue water allocated to irrigated agriculture yields the lowest economic value among all alternative uses and it is often associated with significant environmental externalities (Zehnder et al. 2003).

The ratio of irrigated areas or rainfed areas to total crop areas indirectly shows the dependency on blue or green water resources for agricultural production. As calculated by Fader et al. (2011), the largest share of the water used in agriculture is green (84\%) as well as the virtual water 'embedded' in exports $(94 \%)$, 'moving' generally from green water-

\footnotetext{
${ }_{5}^{5}$ It could be argued, however, that the price of agricultural land reflects fertility and peculiar climatic conditions, including green water availability.

${ }^{6}$ Blue water used in irrigated agriculture yields the lowest economic value among all other options while being associated with significant negative environmental externalities - such as water logging, salinisation, soil degradation (Zehnder et al. 2003).
} 
abundant countries to blue-water based countries. Crop production at the global scale is mainly rainfed and the ratio of rainfed or irrigated areas to total crop production have a high geographical correlation with virtual water 'importers' and 'exporters' (Yang et al. 2006). In other words, water-abundant countries rely on green water resources; vice versa, in waterscarce countries the dependency on blue water is generally higher.

The importance of keeping blue and green water distinct in a context of policy assessment should now be clear. By importing goods one country can free up those water inputs that would have been needed to produce the goods domestically. As in water-scarce countries, blue water is generally relatively more abundant than green water, the import of food commodities potentially enables this water to be re-allocated to uses yielding 'more value per drop' than irrigated agriculture. In order to understand the significance of international trade in terms of water, it is thus necessary to appraise whether the water that is not used for agricultural production in the importing economies is blue or green.

\section{A Test Case: Virtual Water Trade in the Mediterranean}

In the previous section, we argued that systemic (rather than only direct) and blue/green (rather than only global) water usage should be considered in virtual water 'trade' analysis. From a practical point of view, however, would the improved estimates of virtual water 'flows' fundamentally change the (qualitative) results, possibly bringing about different policy implications?

To explore this issue, we estimated virtual water 'trade' flows for a set of countries in the Mediterranean, using three alternative methodologies: the standard one (à la Hoekstra and Hung), the systemic one (where virtual water coefficients are corrected using input-output matrices), and the systemic one applied only to blue water. The Mediterranean is an especially interesting test case and it has been the subject of several virtual water studies. This should not come as a surprise, as the Mediterranean region is one of the most water-challenged areas in the world. Water issues regard not only the overall limited water supply throughout the region, but also the uneven distribution of the resource. The results of the estimation exercise, as well as a cursory description of the procedure, are presented in the Appendix. In the following, we focus on some key results, highlighting the implications of using different methods to calculate virtual water variables.

Figure 1 presents the percentage variation, with respect to estimates obtained with the standard method, in water requirement per unit of output for the Fruit and Vegetables industry,

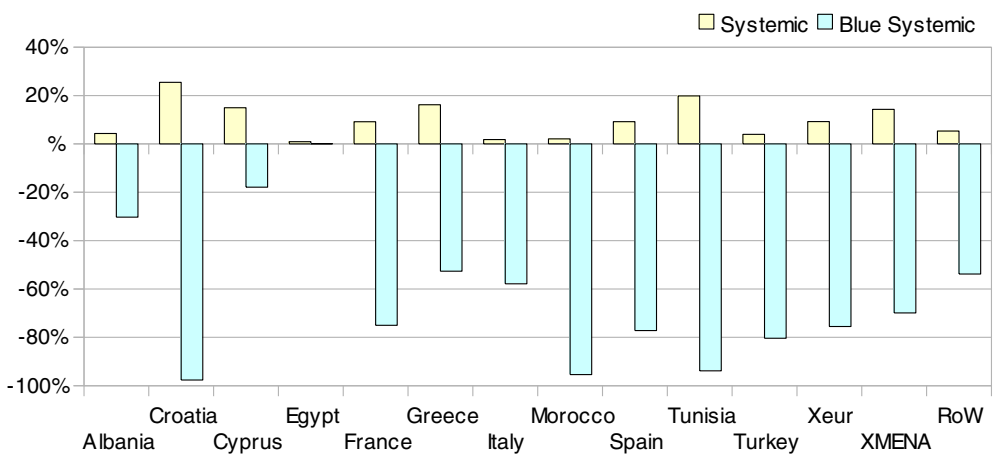

Fig. 1 Percent changes in estimates (from those obtained with the standard method) for water requirements per unit of output $\left(\mathrm{m}^{3} / \mathrm{M} \$\right)$. Fruit and Vegetables industry 
when (i) the IO-based method is adopted to overall water consumption (light brown bar); (ii) the method is only applied to blue water (light blue bar). The results are shown for 11 Mediterranean countries and three residual macro-regions. ${ }^{7}$

Not surprisingly, systemic (IO) coefficients are always larger than those obtained when the standard method is applied, because indirect water consumption is included. Also, blue (systemic) water coefficients are always smaller, as blue water is only a share of overall water consumption. ${ }^{8}$ What is important to notice here is that the ranking among countries in terms of water productivity, or water intensity, may be very different when the focus is on blue water resources and interdependencies between industries are accounted for. For example, countries like Morocco and Tunisia turn out to be much less blue water intensive than Egypt. This means that exporting one dollar of fruits or vegetables from Morocco or Tunisia entails a much lower consumption of precious blue water resources.

Figure 2 shows virtual water 'trade' balances (virtual water 'imports' minus virtual water 'exports') for some representative countries, estimated using the standard methodology (purple bar), the systemic/IO one (light brown bar), and the blue + systemic one (light blue bar).

The general purpose of computing virtual water 'trade' balances is assessing whether a country is a net virtual water 'importer' or 'exporter'. In this respect, Fig. 2 highlights that the results can be dramatically different when a more appropriate methodology to estimate virtual water coefficients is adopted. Indeed:

- Former net virtual 'exporters' (e.g, Turkey and, more importantly, France) become (blue) virtual water 'importers';

- Significant import volumes remain so if only the blue water component is considered (e.g., Morocco and Tunisia);

- Higher virtual inflows of water are estimated when systemic inter-dependencies are considered (e.g., Greece and Spain).

Another interesting exercise is assessing the gains in terms of water resources to water 'importing' countries. This is done by computing how much water (total or blue) would be needed if imports were instead produced domestically, while subtracting from the latter the water consumed to produce exported goods. This new kind of balance expresses how much extra water would be necessary if a country was not involved in international trade, at given (unchanged) levels of domestic consumption.

Figure 3 (analogous of Fig. 2) illustrates some interesting results for a set of representative countries.

The findings illustrated in Fig. 3 confirm that the application of different methodologies for the estimation of virtual water 'trade' flows may lead to strikingly different outcomes:

- Depending on which method is used, a country can be a net gainer or loser, in terms of virtual water resources;

- The gains obtained by a country like Egypt are much higher than initially estimated, when blue water and system effects are considered;

- Countries like Morocco, Tunisia and Turkey appear to gain from trade, the more so when systemic effects are taken into account. Yet, they are not gaining blue water resources.

\footnotetext{
${ }^{7}$ Xeur $=$ Rest of Europe, XMENA $=$ Rest of Middle East and North Africa, RoW $=$ Rest of the World.

${ }^{8}$ Actually, the total variation of blue systemic coefficients is due to the overlapping of two counteracting effects: (a) the inclusion of indirect consumption, (b) the consideration of the blue water share. The second effect dominates.
} 


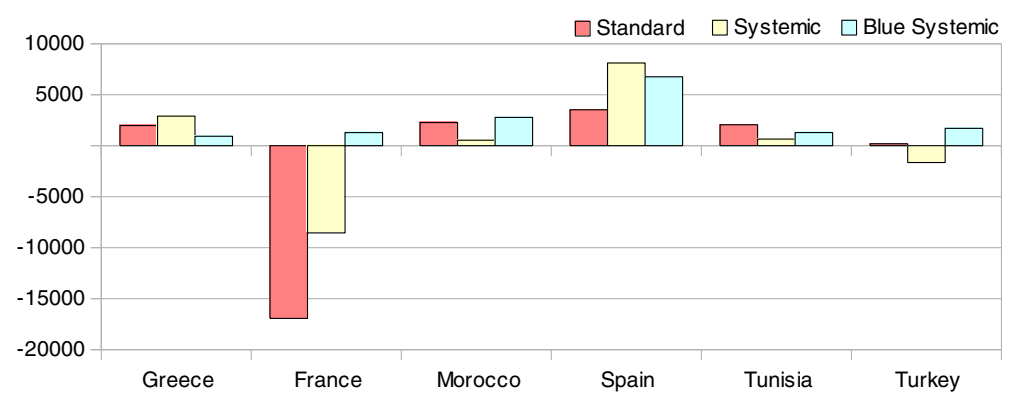

Fig. 2 Virtual water 'trade' balance estimates, obtained with standard, systemic and blue + systemic methods

We argued above that analysing systemic virtual water 'trade', while focusing on blue water, allows to get a more meaningful understanding of the implications of international trade in terms of water. The results of our numerical test support this argument. Furthermore, they suggest that neglecting these effects may lead to biased estimates and erroneous interpretations.

\section{Conclusions}

A general principle of economics states that trade can improve upon the allocation of resources, including water. The concept of virtual water was introduced to better understand what this principle implies in terms of resources management and possibly how this automatic, market-driven mechanism may interact with specific water systems policies.

From this perspective, the fruitfulness of the virtual water concept is obviously dependent on the techniques used to estimate virtual water variables and parameters. In this paper, we argued that a correct estimation of virtual water parameters should consider the indirect consumption of water, due to the use of intermediate production factors, as well as the fact that blue water is what really matters in many circumstances. Indeed, as only blue water can be transferred to alternative uses, the relevance of virtual water trade is linked to the possibility of diverting blue water away from agriculture, where its marginal value is generally low, to other utilizations

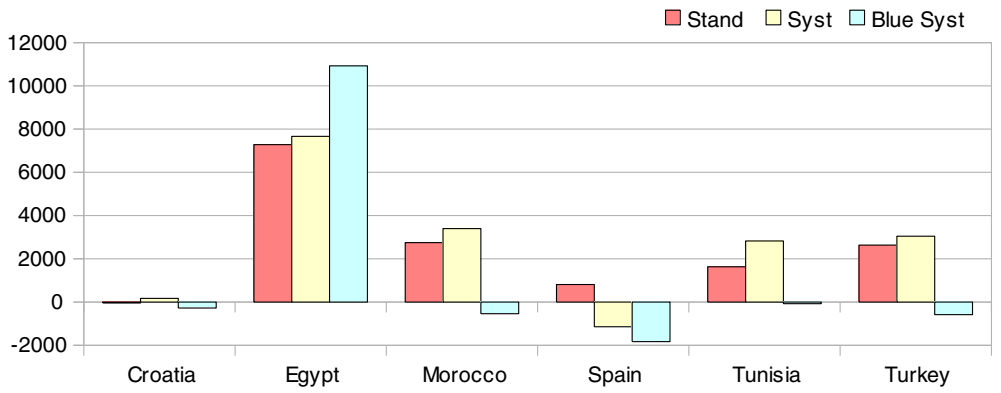

Fig. 3 Estimates of potential virtual water 'savings', obtained with alternative methods 
(drinking, industrial uses, etc.), where the marginal value is higher. By contrast, green water cannot be moved, so 'saving' green water is a quite meaningless concept.

To our knowledge, this is the first paper to show that, by combining input-output techniques with blue water accounting, it is possible to get not only more accurate estimates of virtual water 'flows' in international trade, but also to obtain dramatically different results, from a qualitative point of view.

Previous estimates of virtual water 'flows' and 'trade' could have been flawed by their lack of consideration of indirect water usage and by not fully differentiating between blue and green water resources. We showed in the paper that estimates of water requirement per unit of output are generally higher when systemic effects are accounted for, whereas they are lower when only blue water is considered. What really changes the picture, however, it not the fact that estimates are all biased upward or downward, but that the shift does not occur homogeneously among the sectors. Systemic water requirements are higher in those industries that are highly integrated with the rest of the economy, using a lot of intermediate factors, which themselves require water. Therefore, previous studies have underestimated the water needs of those integrated sectors. Similarly, as the ratio between blue and green water consumption is higher in arid countries (relying relatively more on irrigation), previous studies have underestimated the water needs of those countries.

Acknowledgments This study has been partly funded and realised in the context of EU FP7 project WASSERMed (Grant agreement number 244255, http://www.wassermed.eu). The authors are grateful to Tony Allan for his many comments and suggestions on earlier draft of this work, as well as to Holger Hoff for providing data about green/blue water shares.

\section{Appendix}

Data for 14 Mediterranean economies was obtained through aggregation from the 7.1 Global Trade Analysis Project (GTAP) database (see http://www.gtap.org). The following countries are considered: Albania, Croatia, Cyprus, Egypt, France, Greece, Italy, Morocco, Spain, Tunisia, Turkey, Rest of Europe, Rest of Middle East and North Africa, Rest of the World. Seven agricultural industries are taken into account: Cereals, Rice, Sugar, Oilseeds, Vegetable and Fruits, Wheat, Other Crops.

Water requirements per crop were derived from Chapagain and Hoekstra (2004), and expressed as water required for one million of dollars value of industry output in agricultural sectors. Green water consumption, by country, has been estimated by the eco-hydrological model LPJmL. Blue water consumption has been estimated by multiplying total blue water availability (in each region) by the percentage of irrigated land over total agricultural area (source: http://faostat.fao.org).

Figure 4 shows, for each country/region, the estimated green and blue water shares.

Figures 5, 6, 7, 8 and 9 are analogous to Fig. 1 and present the percentage variation, with respect to estimates obtained with the standard method, in water requirement per unit of output for all other agricultural industries.

Table 1 displays virtual water trade flows, computed using the systemic method for blue water, for all pairs of countries/regions. 


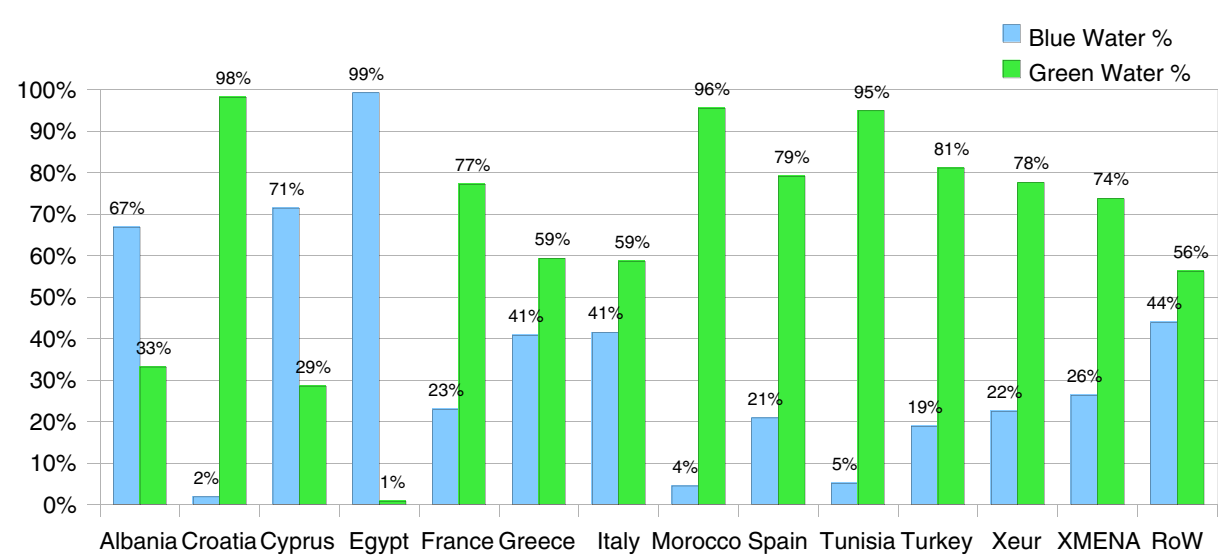

Fig. 4 Shares of blue and green water used in agricultural industries

\section{Rice}

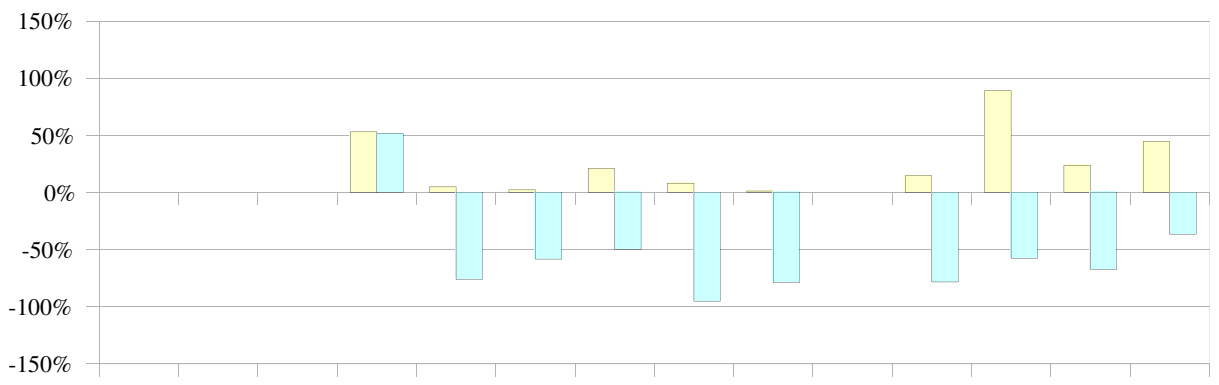

AlbaniaCroatiaCyprus Egypt FranceGreece Italy Morocco Spain Tunisia Turkey Xeur XMENA RoW

Fig. 5 Percent changes in estimates (from those obtained with the standard method) for water requirements per unit of output $\left(\mathrm{m}^{3} / \mathrm{M} \$\right)$. Rice industry

\section{Wheat}

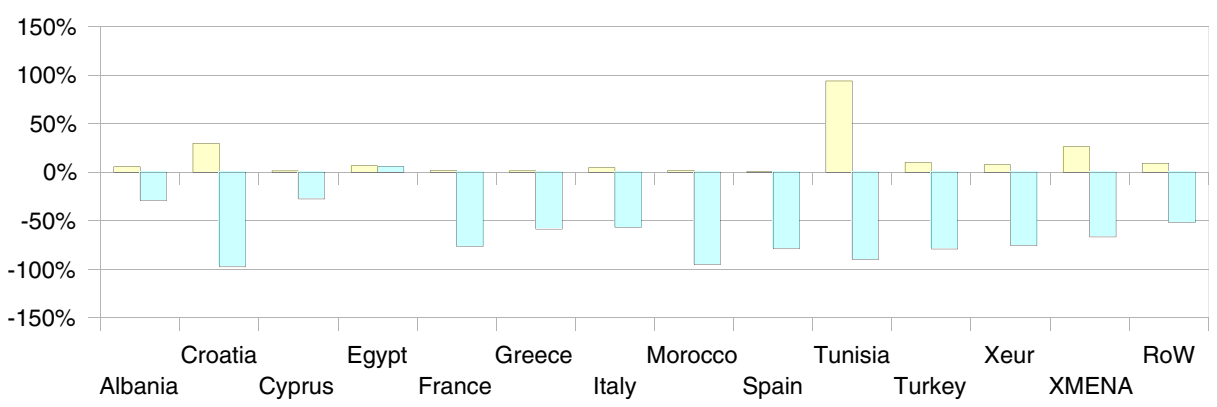

Fig. 6 Percent changes in estimates (from those obtained with the standard method) for water requirements per unit of output $\left(\mathrm{m}^{3} / \mathrm{M} \$\right)$. Wheat industry 


\section{Cereals}

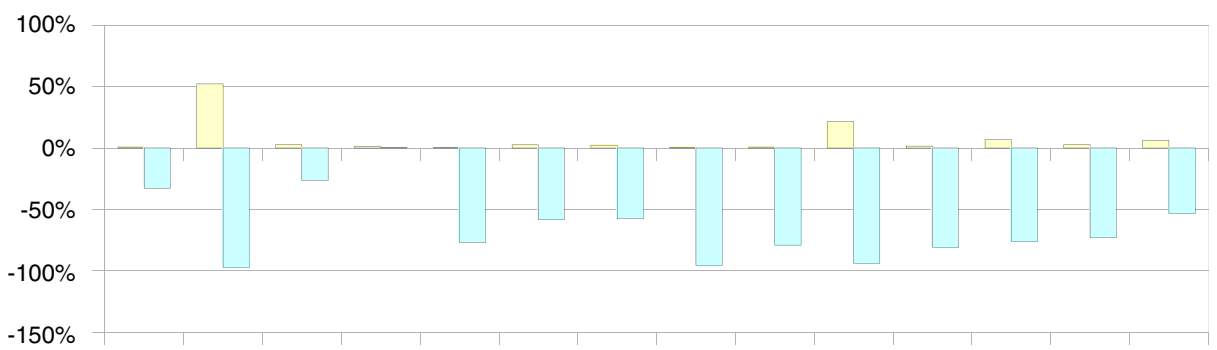

Albania CroatiaCyprus Egypt France Greece Italy Morocco Spain Tunisia Turkey Xeur XMENA RoW

Fig. 7 Percent changes in estimates (from those obtained with the standard method) for water requirements per unit of output $\left(\mathrm{m}^{3} / \mathrm{M} \$\right)$. Cereals industry

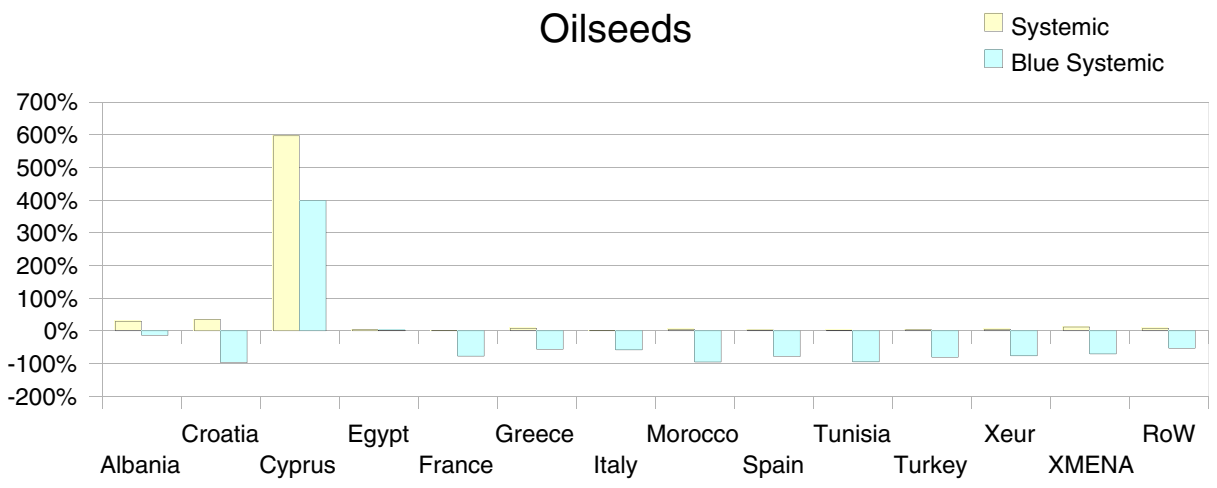

Fig. 8 Percent changes in estimates (from those obtained with the standard method) for water requirements per unit of output $\left(\mathrm{m}^{3} / \mathrm{M} \$\right)$. Oilseeds industry

\section{Sugar}

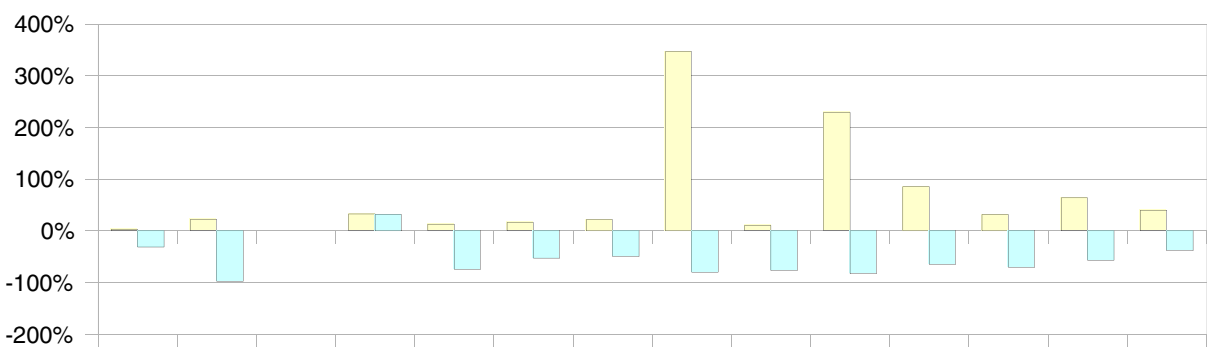

Albania Croatia Cyprus Egypt France Greece Italy Morocco Spain Tunisia Turkey Xeur XMENA RoW

Fig. 9 Percent changes in estimates (from those obtained with the standard method) for water requirements per unit of output $\left(\mathrm{m}^{3} / \mathrm{M} \$\right)$. Sugar industry 


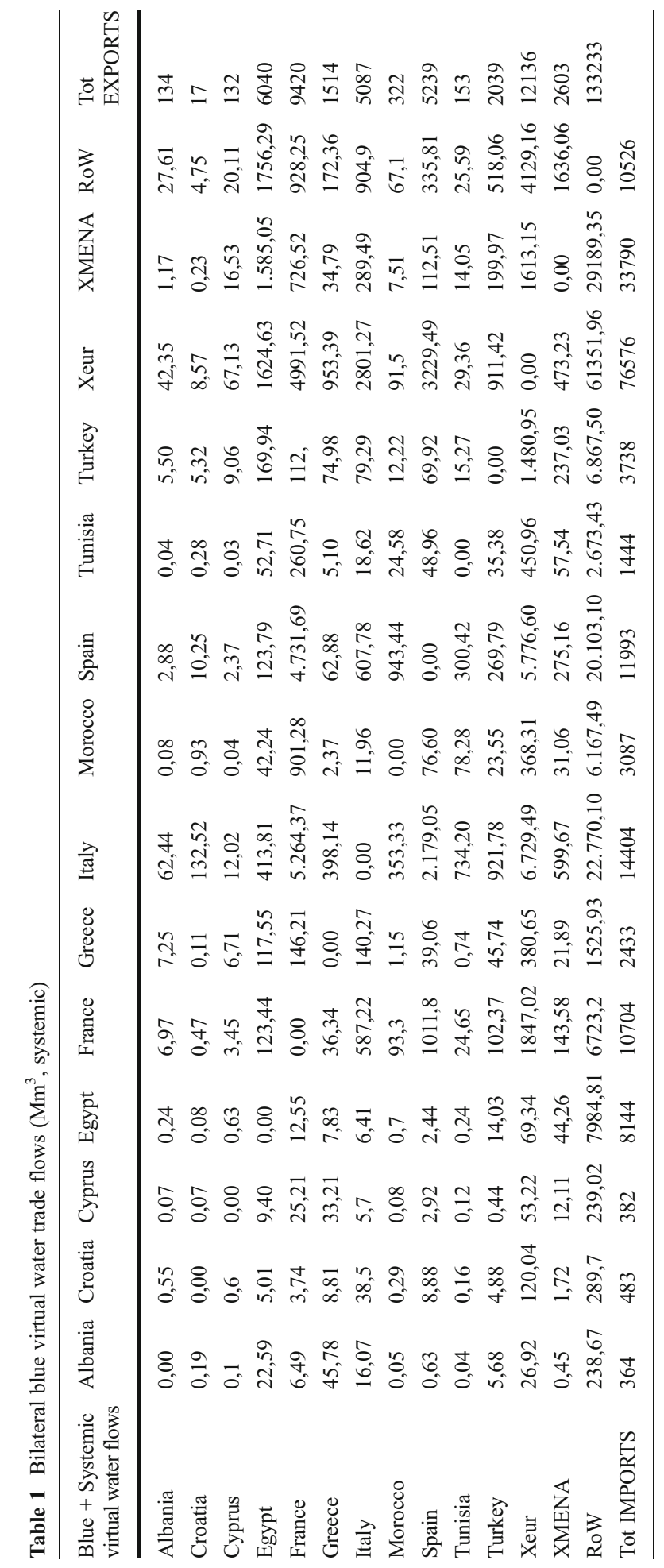




\section{References}

Allan JA (1993) Fortunately there are substitutes for water otherwise our hydro-political futures would be impossible, priorities for water resources allocation and management. ODA, London, pp 13-26

Allan JA (1998) Virtual water: a strategic resource global solutions to regional deficits. Groundwater 36:545546

Atkinson G, Hamilton K, Ruta G, van der Mensbrugghe D (2010) Trade in 'Virtual Carbon': empirical results and implications for policy, policy research working paper, 5194, The World Bank, Washington, D.C

Chapagain AK, Hoekstra AY (2003) Virtual water flows between nations in relation to trade in livestock and livestock products, in value of water research report series, 13, UNESCO-IHE, Delft

Chapagain AK, Hoekstra AY (2004) Water footprint of nations, in value of water research report series, 16, UNESCO-IHE, Delft

Chapagain AK, Hoekstra AY, Savenije HHG (2006) Water saving through international trade of agricultural products. Hydrol Earth Syst Sci 10:455-468

Dabo G, Hubacek K (2007) Assessment of regional trade and virtual water flows in China. Ecol Econ 61 (1):159-170

Dietzenbacher E, Velázquez E (2006) Virtual water and water trade in Andalusia. A study by means of an input-output model, Working Papers 06.06, Universidad Pablo de Olavide, Department of Economics, Sevilla

Dietzenbacher E, Velázquez E (2007) Analysing andalusian virtual water trade in an input-output framework. Reg Stud 41(2):185-196

Fader M, Gerten D, Thammer M, Heinke J, Lotze-Campen H, Lucht W, Cramer W (2011) Internal and external green-blue agricultural water footprints of nations, and related water and land savings through trade. Hydrol Earth Syst Sci Discuss 8:483-527

Falkenmark M (1995) Land-water linkages: a synopsis. land and water integration and river basin management. FAO Land Water Bull 1:15-16

Feng K, Hubacek K, Minx J, Siu YL, Chapagain A, Yu Y, Guan D, Barret J (2011) Spatially explicit analysis of water footprints in the UK. Water 3:47-63

Hoekstra AY, Hung PQ (2002) Virtual water trade: a quantification of virtual water flows between nations in relation to international crop trade, value of water research report series, 12 , UNESCOIHE, Delft

Huang XR, Pei YS, Liang C (2011) Input-output method for calculating the virtual water trading in Ningxia. Advances in Water Science 27(3):135-139

Lenzen M, Peters GM (2010) How city dwellers affect their resource hinterland. J Ind Ecol 14:73-90

Leontief W (1951) Input-output economics. Oxford University Press, 2nd edition reprinted 1986, New York

Merrett S (2003) Virtual water and the Kyoto consensus. Water Altern 28(4):540-542

Oki T, Sato M, Kawamura A, Miyake M, Kanae S, Musiake K (2003) Virtual water trade to Japan and in the world. In: Hoekstra AY (ed) Virtual water trade: proceedings of the International Expert Meeting on Virtual Water Trade, Value of Water Research Report Series, 12, UNESCO-IHE, Delft

Reimer JJ (2012) On the economics of virtual water trade. Ecol Econ 75:135-139

Rockström J, Gordon L, Falkenmark M, Folke C, Engvall M (1999) Linkages among water vapor flows, food production and terrestrial ecosystems services. Conserv Ecol 3(2):1-28

Velázquez E (2006) An input-output model of water consumption: analysing intersectoral water relationships in Andalusia. Ecol Econ 56:226-240

Wang Y, Xiao H, Wang R (2009) Water scarcity and water use in economic systems in Zhangye City, Northwestern China. Water Resour Manag 23:2655-2668

Yang H, Wang L, Abbaspour KC, Zehnder AJB (2006) Virtual water highway: water use efficiency in global trade. Hydrol Earth Syst Sci Discuss 3:1-26

Yu Y, Hubacek K, Feng K, Guan D (2010) Assessing regional and global water footprints for the UK. Ecol Econ 69:1140-1147

Zehnder AJB, Yang H, Schertenleib R (2003) Water issues: the need for actions at different levels. Aquat Sci 65:1-20

Zhang H, Shuiying M, Zhang X, Wang Y (2010) Analysis of Tianjin virtual water trade based on input-output model, presented at the International Conference on System Science and Engineering, Taipei

Zhang Z, Shi M, Yang H, Chapagain A (2011) An input-output analysis of trends in virtual water trade and the impact on water resources and uses in China. Econ Syst Res 23(4):431-446

Zhao X, Chen B, Yang ZF (2009) National water footprint in an input-output framework. A case study of China 2002. Ecol Model 220:245-253 
Zhao X, Yang H, Yang Z, Chen B, Qin Y (2010) Applying the input-output model to account for water footprint and virtual water trade in the Haihe river basin in China. Environ Sci Technol 44 (23):9150-9156

Zimmer D, Renault D (2003) Virtual water in food production and global trade: review of methodological issues and preliminary results. In: Hoekstra AY (ed) Virtual water trade: proceedings of the International Expert Meeting on Virtual Water Trade, Value of Water Research Report Series, 12, UNESCO-IHE, Delft 